\title{
Bone Necrosis After Pulp Treatment of Temporary Molar with Calcium Hydroxide: In Vivo Confirmation
}

\author{
Cristina Cardoso-Silva ${ }^{1 *}$, Maria Llanes ${ }^{2}$ and Elena Barbería ${ }^{3}$ \\ ${ }^{1}$ Department of Paediatric Dentistry, Faculty of Health Sciences, University Fernando \\ Pessoa, Porto, Portugal \\ ${ }^{2}$ Department of Biomedics and Medicine, University of Algarve, Faro, Portugal \\ ${ }^{3}$ Department of Clinical Odontological Specialities, Faculty of Dentistry, Complutense \\ University of Madrid, Madrid, Spain \\ *Corresponding Author: Cristina Cardoso Silva, Department of Paediatric \\ Dentistry, Faculty of Health Sciences, University Fernando Pessoa, Porto, Portugal.
}

\author{
Received: November 25, 2020 \\ Published: December 16, 2020 \\ (C) All rights are reserved by Cristina \\ Cardoso-Silva., et al.
}

\begin{abstract}
Calcium hydroxide has been used for a variety of purposes in dentistry including pulpotomy of temporary molars. Several studies examining inflammatory response to its use generally demonstrated a mild inflammatory reaction. However, it may cause adverse reactions damaging bone and soft tissues either by direct contact after poor implementation or after ion diffusion. The severity and extent of the lesion depends on the quantity and concentration used, as well as on the time of contact. The following report describes a case of bone necrosis after a pulpotomy with calcium hydroxide in a temporary molar. Pathological analysis confirmed de diagnosis.
\end{abstract}

Keywords: Bone Necrosis; Calcium Hydroxide; Pulpotomy; Temporary Molars; Bone Lesion

\section{Abbreviations \\ $\mathrm{Ca}(\mathrm{OH})_{2}$ : Calcium Hydroxide}

\section{Introduction}

Adverse effects of dental materials may play an important role, since the majority release small amounts of various substances into their physiological environment. Previous studies have shown that dental materials may induce local and systemic adverse effects due to the release of extractable monomers and/or other inorganic and organic ingredients [1].

Calcium hydroxide $\left(\mathrm{Ca}(\mathrm{OH})_{2}\right)$ based compounds are thought to meet most of the requirements of endodontic treatments [1] and has been used for a wide variety of purposes including pulpotomy of temporary molars. It has antimicrobial action, neutralizes microbial organic debris, induces repair with mineralized tissue deposition and hydrolyses the lipid moiety lipopolysaccharide [2].

Several studies examining toxicity inflammatory response to the use of $\mathrm{Ca}(\mathrm{OH})_{2}$ generally demonstrated a mild inflammatory reaction, with an influx of foreign body giant cells. In addition, they showed mild to moderate tissue irritating activities $[3,4]$. However, it may also cause adverse reactions damaging bone and soft tissues either by direct contact after poor implementation [5-7] or after ion diffusion [8]. It has also been described inferior alveolar nerve paraesthesia caused by displacement of calcium hydroxide paste through the apex during endodontic treatment [9]. The severity and extent of lesions depends on the quantity and concentration used, as well as on the time of contact [10].

The following report describes a case of bone necrosis after a pulpotomy with calcium hydroxide in a temporary molar.

\section{Case Report}

A 6-year-old Caucasian male presented to the Paediatric Dental Clinic of the Dentistry Faculty, University Complutense of Madrid, Spain. Parents refer their son attended to the dentist 6 months ago and that an endodontic treatment with calcium hydroxide was performed on the lower right second temporary molar. Few days after, 
they noticed a lesion on the gum which is getting worse since then. Increasingly it looks worse and parents fear it might be a tumour.

Panoramic radiographs dated immediately prior and five months after treatment were provided (Figure 1, 2). History and medical examination did not provide relevant data.

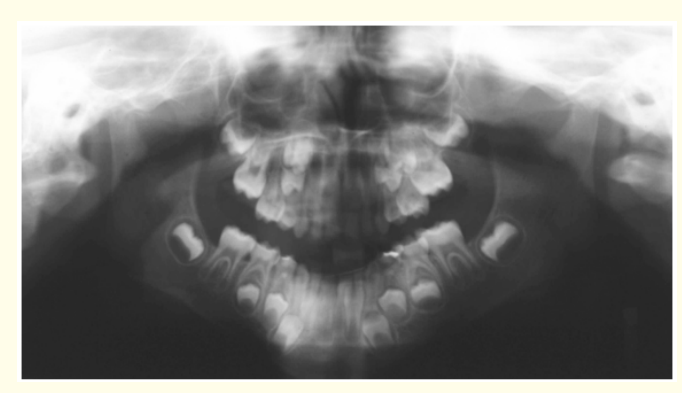

Figure 1: Panoramic radiograph before treatment of lower right temporary molars, provided by the patient.

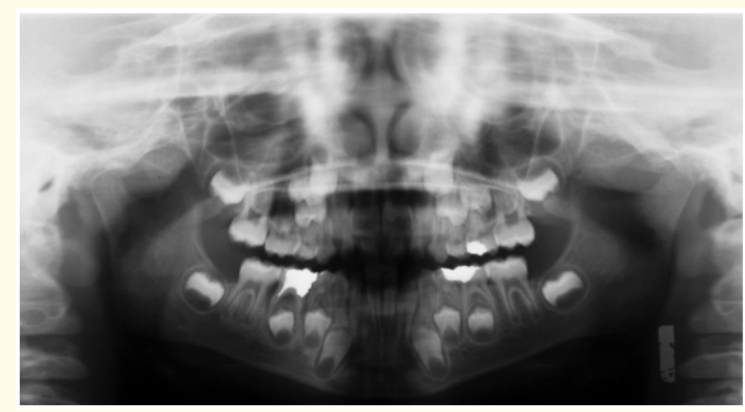

Figure 2: Panoramic radiograph 5 months after treatment of lower right temporary molars, provided by the patient.

Dental examination revealed a mixed dentition, first phase, with overflowing amalgam restorations on the lower right and left molars. Mucous membranes exhibited normal colour and appearance except for the gum surrounding mandibular right first and second molars. In this area, buccal gingiva presented severe retraction with suppuration and exposed bone, completely white and spongy. Lingual gingiva presented mild inflammation. These molars showed increased mobility, indicating a bone sequestrum of the alveolar process.

As it can be observed in the orthopantomography, prior to dental treatment, bone crest height, trabecular bone, and rhizolysis of both primary molars and correspondent premolars development were normal (Figure 1). Five months after treatment, the lower right second temporary molar presented the pulp chamber and root canals partially filled with a radiopaque material. Alveolar bone rarefaction and a distal rotation of the second premolar can also be registered (Figure 2). In the periapical radiograph, no bone is observed distal to the right second molar and there is continuity between cement and bone in the root furcation. In the first temporary molar, restoration is inside pulp chamber, there is caries recurrence, atypical lysis of distal root and enlargement of periodontal space (Figure 3). The dentist who performed the treatment, confirmed the use of an alkaline calcium hydroxide preparation (Dentaflux ${ }^{\circledR}$ ) in the endodontic treatment of the lower right second temporary molar.

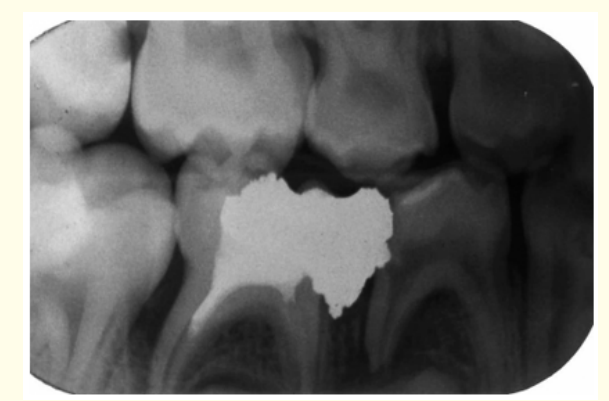

Figure 3: Periapical radiograph revealing restorative material inside the pulp chamber of the first temporary molar. Bone resorption distal to the second temporary molar can be noticed.

On the left side, pulpotomy with white Mineral Trioxide Aggregate (Dentsply ${ }^{\circledR}$ ) and restoration with stainless-steel crowns were indicated and performed on both molars.

On the right side, a probable caustic osteonecrosis with sequestrum of the alveolar process was diagnosed. The extraction of both molars and space maintenance were planned.

After extracting the second temporary molar, a fusion between alveolar bone and the roots furcation could be noticed up to the apex of the distal root, and in every surfaces of the mesial root. Likewise, there was no periodontal ligament in almost all surface of the distal root (Figure 4). The alveolar bone presented a normal bleeding regarding the amount and colour. The second premolar (45) could be observed deep in the alveolus proving the lesion extended till the permanent germ (Figure 5). Systemic antimicrobial therapy was prescribed (Amoxicillin during 1 week) as well as chlorhexidine gluconate bioadhesive gel $(0.2 \%$, every 8 hours for 10 days). The specimens were sent for pathological analysis. 


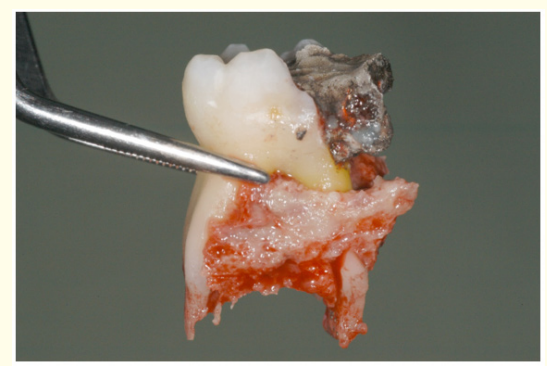

Figure 4: Second temporary molar after extraction exhibiting fusion between alveolar bone and roots furcation in every surfaces of the mesial root.

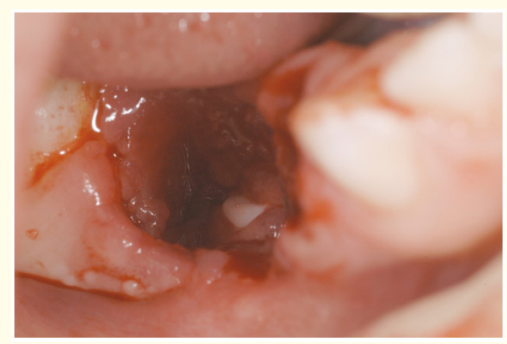

Figure 5: Second premolar can be observed deep in the alveolus proving the lesion extended till the permanent germ.

Two weeks after extractions, the gingiva presented a healthy appearance and the premolar germ still slightly visible (Figure 6). Three weeks after, complete healing could be observed.

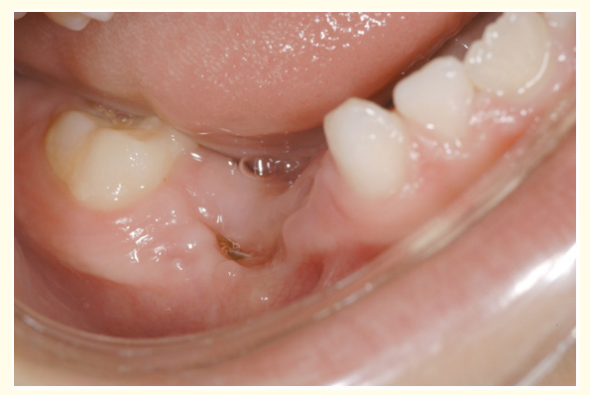

Figure 6: Clinical aspect two weeks after extraction. The premolar germ still slightly visible.

Three months after, gingiva showed a normal aspect and colour (Figure 7). The periapical radiograph exhibited trabecular bone surrounding the second premolar germ but without covering it (Figure 8). Premolars odontogenesis continued normally, however the second premolar germ was superficial and located higher than the first premolar, indicating a change in the eruptive sequence.

One year later, the second right premolar emerged and a hipomineralization defect on the oclusal and vestibular surfaces could be observed (Figure 9).

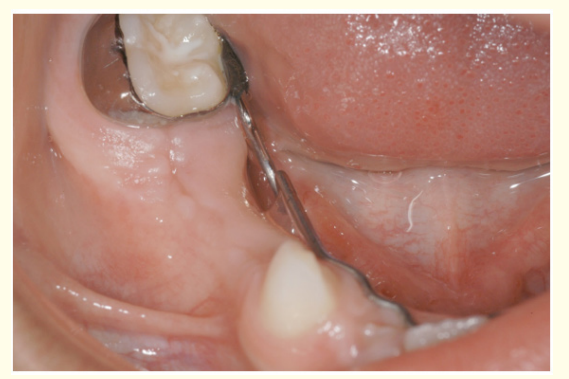

Figure 7: Normal aspect of the gingiva three months after extractions.

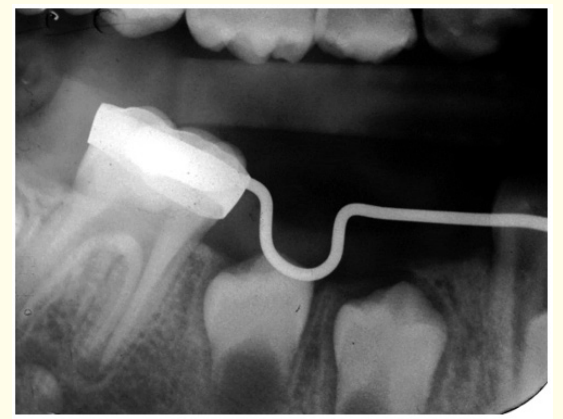

Figure 8: Periapical radiograph three months after extractions. Trabecular bone surrounding the second premolar germ can be observed, but without covering it.

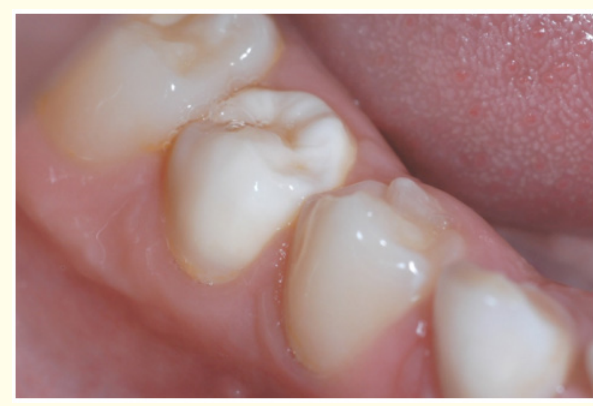

Figure 9: Second right premolar after exhibiting a hipomineralization defect on the oclusal and vestibular surfaces. 


\section{Pathological analysis}

The specimen was preserved in formaldehyde (12\%) and sent for pathological analysis. A molar surrounded by soft tissues and bone fragments was submersed in a decalcifying formic acid solution to detach the amalgam. All other tissues were incorporated in paraffin.

Serial cuts of the entire sample were made to confirm the architectural integrity of the molar. Neither solutions of continuity nor pathological perforations attributable to improper manipulation were found.

Cuttings were stained with hematoxylin-eosin and, randomly, with Masson trichrome, PAS and Gram.

The pulp chamber was fulfilled with granular calcium hydroxide until the radicular furcation communicating with root canals which contains necrotic pulp debris.

In the interface between the calcium hydroxide and the radicular necrotic pulp, there was precipitation of birefringent crystal structures. Root canals, besides some pulp debris, showed some leukocytes (neutrophils) and blood remnants, more abundant in the area surrounding the apexes. The remaining coronal enamel and dentin presented normal appearance (Figure 10). Cement is acellular with empty cementoplastic cavities or with little cellular debris.

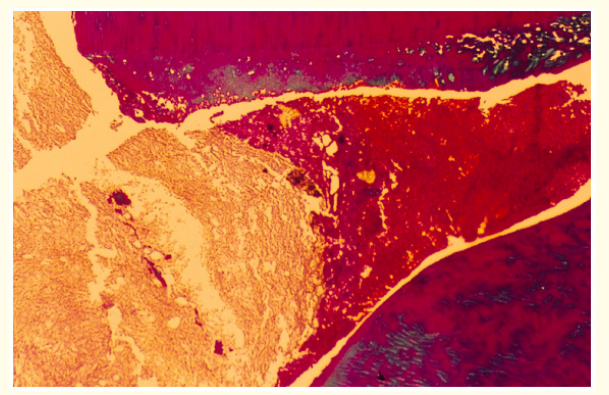

Figure 10: Radicular pulp necrosis and pulp chamber obturation with calcium hydroxide (Tr. Masson x240).

The periodontal ligament was necrotic and there was no gingival epithelium (Figure 11). Some bacterial colonies (cocci, bacilli and gram negative) could be found, in the absence of inflammatory infiltrate.

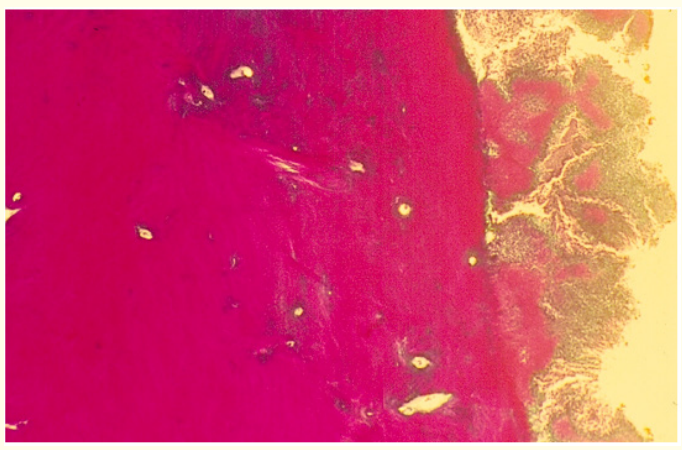

Figure 11: Necrosis of the periodontal ligament without gingival epithelium (Tr. Masson x240).

The bone tissue adherent to the root furcation and external radicular walls was necrotic showing the osteoplastic lagoons completely empty, evidencing the characteristic spongy appearance (Figure 12). Bone marrow with advanced signs of necrosis, was transformed in an unstructured magma, where some bacterial colonies (Gram negative) were found. No mycotic hypha or conidian was identified using the PAS method.

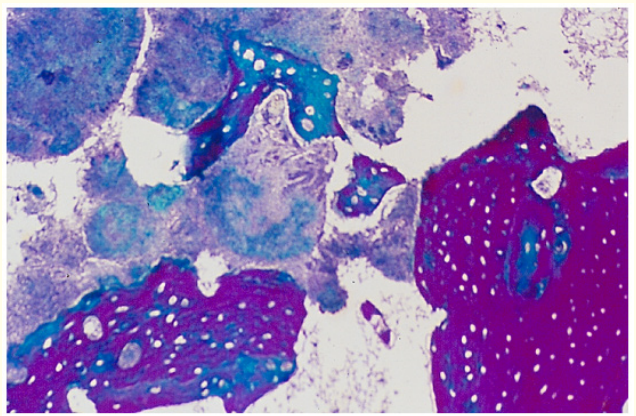

Figure 12: Periradicular bone necrosis with empty osteoplastic lagoons (Tr. Masson x144).

The periodontal soft tissues and bone showed a non-existent or minimal inflammatory infiltration. When present, the inflammatory infiltrate was an acute type and neutrophils were the only cells identified.

Serial cuts showed, uncontroversial, that the pulp chamber walls were intact and without any breaking or entering.

Root canals contained necrotic pulp debris, degraded red blood cells and neutrophils. 
Histopathological diagnosis was necrosis by causticization and the possibility of accidental setting of calcium hydroxide out of the pulp chamber was excluded.

\section{Discussion}

The initiation and stimulation of mineralization, the antibacterial characteristics and the dissolution of necrotic material are the main indications for the extensive use of $\mathrm{Ca}(\mathrm{OH})_{2}$ in dentistry. These properties are mainly correlated to the high $\mathrm{pH}$ [11]. Although different $\mathrm{Ca}(\mathrm{OH})_{2}$ materials may induce a different $\mathrm{pH}$ variation, they always have the capacity to transform a neutral $\mathrm{pH}$ into alkaline [12].

However, not only these positive effects can occur from its necrotizing capacity [11] and side effects such as cell damage [13], persistent inflammatory response [14], gingival and connective tissue necrosis $[15,16]$, bone tissue necrosis [17], paraesthesia of the inferior alveolar nerve [11] and some cytotoxic effects [2] have been described and should not be underestimated [5-7,9,15,18].

Iatrogenic chemical burns caused by chemical agents used in dental pulp therapy such as $\mathrm{Ca}(\mathrm{OH})_{2}$ have been described. SantosPinto., et al. reported a case where the dentist inserted a pledget of cotton wool, moistened in $\mathrm{Ca}(\mathrm{OH})_{2}$ solution, in the pulp chamber to control bleeding and the expressed solution was swallowed by the patient causing chemical burns on the buccal mucosa [10]. In these situations, the progression of the lesion cannot be stopped by just removing or neutralizing the etiologic agent as alkaline substances keep on destroying the tissues, resulting in ulcers and progressive lesions reaching deeper tissue layers [19].

De Moor., et al. reported 11 clinical cases of extensive overflow of $\mathrm{Ca}(\mathrm{OH})_{2}$ with no occurrence of relevant symptoms [20]. Nevertheless, there are other reports of gingival necrosis after contact with $\mathrm{Ca}(\mathrm{OH})_{2}$ requiring surgical removal of the extruded material [11] or, in some cases, curettage and irrigation of the necrotic tissue [15].

Calcium hydroxide has been successfully used to treat periapical lesion-induced paraesthesia [21] and its deliberated extrusion in the periradicular tissues, in cases of large lesions or periapical cysts, has been advocated in the literature [22]. Nevertheless, when the paste extrude beyond the apex, it may affect the inferior alveolar nerve [9,23-25]. The need for a careful application of this material into root canals should be emphasized [25], as well as the necessity for its removal as soon as possible in the case of developing symptoms, since the nerve can regain normal function and sensibility after early surgical removal of the material [9].

Some previous studies concluded that no or only mild and transient problems occur if $\mathrm{Ca}(\mathrm{OH})_{2}$ comes into direct contact with surrounding bone, as in displacement through the apical foramen $[26,27]$. On the contrary, the present case report shows that, even without direct contact, bone necrosis occurred. The serial cuts confirmed the integrity of the molar treated by pulpotomy with $\mathrm{Ca}(\mathrm{OH})_{2}$ and the inexistence of solutions of continuity nor pathological perforations. The authors suggest the ionic diffusion of $\mathrm{Ca}(\mathrm{OH})_{2}$ through the dentinal tubules, as reported by Gomes., et al. as an explanation to the harmful effect caused by causticizing [8].

As a consequence of the early extractions performed in the case reported, the eruptive sequence of the succeeding pre-molars was altered, which could lead to oclusal development complications. There was also a hipomineralization defect on the oclusal surface of the premolar beneath the affected molar. These findings highlight the importance of choosing a dressing material which ensures clinical and radiological success and allows a physiological exfoliation of the treated temporary molars without interfering with the permanent germ in beyond.

Although $\mathrm{Ca}(\mathrm{OH})_{2}$ has been recognized as a pulp dressing agent for pulpotomy of temporary molars [28], currently there are alternatives, such as Mineral Trioxide Aggregate (MTA), which revealed higher success rates and without the harmful effects of $\mathrm{Ca}(\mathrm{OH})_{2}$ [29]. When compared to the gold-standard Formocresol, MTA showed more favourable results [30]. In a long term evaluation of pulpotomy in temporary molars performed with Grey and White MTA in a sample of 233 primary molars with a maximum followup period of 84 months, both types of MTA presented high levels of clinical and radiographic success, with a very good biologic response confirmed by the presence of dentine bridges and pulp canal stenosis [31].

\section{Conclusion}

The serial cuts confirmed incontrovertibly the integrity of the treated molar proving there was no direct contact of $\mathrm{Ca}(\mathrm{OH})_{2}$ and the surrounding area. The ionic diffusion of $\mathrm{Ca}(\mathrm{OH})_{2}$ through the dentinal tubules could explain the harmful effect of bone necrosis caused by causticizing. Mineral trioxide aggregate have already demonstrated higher success rates and without the harmful effects 
of $\mathrm{Ca}(\mathrm{OH})_{2}$ described in the literature, and should therefore be indicated as a substitute for pulpotomy of temporary molars.

\section{Acknowledgements}

The authors would like to express their recognition to Dr. Felipe Llanes for his generous collaboration and expertise in obtaining the histology.

\section{Conflict of Interest}

The authors have no conflicts of interest to disclose.

\section{Bibliography}

1. Huang TH., et al. "Root canal sealers induce cytotoxicity and necrosis". Journal of Materials Science: Materials in Medicine 15 (2004): 767-771.

2. Barbosa SV., et al. "Cytotoxicity of endodontic irrigants containing calcium hydroxide and sodium lauryl sulfate on fibroblasts derived from mouse L929 cell line". Brazilian Dental Journal 20 (2009): 118-121.

3. Zmener 0. "Evaluation of the apical seal obtained with two calcium hydroxide based endodontic sealers". International Endodontic Journal 20 (1987): 87-90.

4. Tronstad L., et al. "Solubility and biocompatibility of calcium hydroxide-containing root canal sealers". Endodontics in Dental Traumatology 4 (1988): 152-159.

5. Hannuksela M., et al. "Caustic ulcers caused by cement". British Journal of Dermatology 95 (1976): 547-549.

6. Lindgren P., et al. "Severe facial ischemia after endodontic treatment". Journal of Oral and Maxillofacial Surgery 60 (2002): 576-579.

7. Luong KV and Nguyen LT. "Cement burn". Journal of Family Practice 41 (1995): 601-602.

8. Gomes IC., et al. "Diffusion of calcium through dentin". Journal of Endodontics 22 (1996): 590-595.

9. Ahlgren FK., et al. "Displaced calcium hydroxide paste causing inferior alveolar nerve paraesthesia: report of a case". Oral Surgery, Oral Medicine, Oral Pathology, Oral Radiology, and Endodontology 96 (2003): 734-737.

10. Santos-Pinto L., et al. "Iatrogenic chemical burns caused by chemical agents used in dental pulp therapy". Burns 30 (2004): 614-615.

11. De Bruyne MAA., et al. "Necrosis of the gingiva caused by calcium hydroxide: a case report". International Endodontic Journal 33 (2000): 67-71.
12. Gencay K., et al. "In vitro evaluation of $\mathrm{pH}$ changes induced by calcium hydroxide liners". Quintessence International 35 (2004): 560-562.

13. Siqueira-Jr JF and Lopes HP. "Mechanisms of antimicrobial potencial of calcium hydroxide: a critical review". International Endodontic Journal 32 (1999): 361-369.

14. Nelson-Filho P., et al. "Connective tissue responses to calcium hydroxide-based root canal medicaments". International Endodontic Journal 32 (1999): 303-311.

15. Bramante CM., et al. "Alveolar mucosa necrosis induced by utilisation of calcium hydroxide as root canal dressing". International Dental Journal 58 (2008): 81-85.

16. Himel VT., et al. "Evaluation of repair of mechanical perforations of the chamber floor using biodegradable tricalcium phosphate or calcium hydroxide". Journal of Endodontics 11 (1985): 161-165.

17. Andreasen JO and Kristerson L. "The effect extra-alveolar root filing with calcium hydroxide on periodontal healing after replantation of permanent incisors in monkeys". Journal of Endodontics 7 (1981): 349-354.

18. Boiesen J and Brodin P. "Neurotoxic effect of two root canal sealers with calcium hydroxide on rat phrenic nerve in vitro". Endodontics in Dental Trauma 7 (1991): 588-593.

19. Yano K., et al. "Experimental study on alkaline skin injuriesperiodic cahnges in subcutaneous tissue $\mathrm{pH}$ and the effects exerted by washing". Burns 19 (1993): 320-323.

20. De Moor RJ and De Witte AM. "Periapical lesions accidentally filled with calcium hydroxide". International Endodontic Journal 35 (2002): 946-958.

21. Ahonen $\mathrm{M}$ and Tjäderhane L. "Endodontic-related paraesthesia: a case report and literature review". JOE 37 (2011): 14601464.

22. Ioannidis K., et al. "Lack of periradicular healing and gradually increasing swelling two years after intentional extrusion of calcium hydroxide into periapical lesion: report of a case". Oral Surgery, Oral Medicine, Oral Pathology, Oral Radiology, and Endodontology 109 (2010): e86-e91.

23. Yatsuhashi T., et al. "Inferior alveolar nerve paresthesia relieved by microscopic endodontic treatment". Bulletin of Tokyo Dental College 44 (2003): 209e212.

24. Sharma S., et al. "Severe tissue necrosis following intra-arterial injection of endodontic calcium hydroxide: a case series". Oral Surgery, Oral Medicine, Oral Pathology, Oral Radiology, and Endodontology 105 (2008): 666e669. 
25. Olsen JJ., et al. "Nerve lesions following apical extrusion of non-setting calcium hydroxide: A systematic case review and report of two cases". Journal of Craniomaxillofacial Surgery 42 (2014): 757-762.

26. Foreman PC and Barnes IE. "A review of calcium hydroxide". International Endodontic Journal 23 (1990): 283-297.

27. Maalouf EM and Gutmann JL. "Biological perspectives on the nonsurgical endodontic management of periradicular pathosis”. International Endodontic Journal 27 (1994): 154-162.

28. Caruso S., et al. "Clinical and radiographic evaluation of biodentine versus calcium hydroxide in primary teeth pulpotomies: a retrospective study". BMC Oral Health 18 (2018): 54.

29. Moretti A., et al. "The effectiveness of mineral trioxide aggregate, calcium hydroxide and formocresol for pulpotomies in primary teeth". International Endodontic Journal 41 (2008): 547-555.

30. Juneja P and Kulkami S. "Clinical and radiographic comparison of biodentine, mineral trioxide aggregate and formocresol as pulpotomy agents in primary molars". European Archives of Paediatric Dentistry 18 (2017): 271-278.

31. Cardoso-Silva C., et al. "Clinical study of mineral trioxide aggregate in primary molars. Comparison between grey and white MTA - a long term follow-up (84 months)". Journal of Dentistry 39 (2011): 187-193.

\section{Assets from publication with us}

- Prompt Acknowledgement after receiving the article

- Thorough Double blinded peer review

- Rapid Publication

- Issue of Publication Certificate

- High visibility of your Published work

Website: www.actascientific.com/

Submit Article: www.actascientific.com/submission.php

Email us: editor@actascientific.com

Contact us: +919182824667 